\title{
Visualizing Climate Change Adaptation: An Effective Tool for Agricultural Outreach? 0
}

\author{
RACHEL E. SCHATTMAN ${ }^{\mathrm{a}, \mathrm{b}}$ \\ U.S. Department of Agriculture Northeast Climate Hub, Burlington, Vermont \\ Stephanie E. Hurley ${ }^{\mathrm{c}}$ AND Holly L. GReEnleAF \\ Department of Plant and Soil Sciences, University of Vermont, Burlington, Vermont \\ MEREDITH T. NILES ${ }^{\mathrm{c}, \mathrm{d}}$ \\ Department of Nutrition and Food Sciences and Food Systems Program, \\ University of Vermont, Burlington, Vermont \\ MARTHA CASWELL \\ Department of Plant and Soil Sciences, and Agroecology and Livelihoods Collaborative, \\ University of Vermont, Burlington, Vermont
}

(Manuscript received 24 April 2019, in final form 19 September 2019)

\begin{abstract}
Landscape photovisualizations (PVZs) are digitally altered photographs that show existing landscapes altered to include a simulated future scenario. They are commonly used to support dialogue and decisionmaking in multistakeholder contexts. In agricultural sectors, stakeholders increasingly must contend with pressures to adapt to climatic changes and shifts in weather patterns. This study examines the potential of PVZs to engage agricultural stakeholders about climate change adaptation, specifically around best management practices (BMPs). In 2015, survey data were collected $(n=133)$ at six agricultural conferences Vermont. Participants were asked about their climate change knowledge, perceptions of adaptation, and their intentions to adopt or recommend one or more of the following BMPs: riparian buffers, drainage tiles with constructed wetlands, retention ponds, and silvopasture. In addition, respondents were asked about how well PVZs did or did not clarify their understanding of each BMP and its associated limiting factors. Results from five multivariate ordered logit models show an increase in interest among some agricultural stakeholders in adopting a BMP (among farmers) or recommending a BMP (among agricultural advisors) after seeing a PVZ depicting that practice. Interest in adoption or recommendation of BMPs was also more likely among respondents who believe that it is important for farms to adapt to climate change. Although PVZs are not common in agricultural outreach programs, these results suggest that PVZs are relevant to agricultural education and land-use decision-making, specifically in the domain of climate change adaptation.
\end{abstract}

Supplemental information related to this paper is available at the Journals Online website: https://doi.org/10.1175/WCAS-D-190049.s1.

a ORCID: 0000-0001-7177-3914.

${ }^{\mathrm{b}}$ Affiliate, Gund Institute for the Environment, University of Vermont, Burlington, Vermont.

${ }^{\mathrm{c}}$ Fellow, Gund Institute for the Environment, University of Vermont, Burlington, Vermont.

${ }^{\mathrm{d}}$ ORCID: 0000-0002-8323-1351.

Corresponding author: Rachel E. Schattman, rachel.schattman@maine.edu 


\section{Introduction}

Climate change and shifts in weather patterns are expected to present many challenges to agricultural sectors worldwide (Hatfield et al. 2018; Walthall et al. 2012), as changing temperatures, precipitation regimes, pest and disease pressure, and rising instances of extreme weather events put increasing pressure on existing productions systems (Gowda et al. 2018). Agricultural systems are vulnerable to changing climatic conditions, with potential impacts spanning economic, ecological, and social concerns (Schattman et al. 2014). In the United States and globally, there is a need for new and increased outreach and programing to assist in discussions and decision-making processes regarding agricultural adaptation to climate change.

Landscape photovisualizations (PVZs) are simulated images of potential future changes to landscapes or the built environment. There is potential for PVZs to support efforts at local and regional levels to increase climate adaptation and mitigation activities. The strategic application of PVZs to agriculture is especially compelling, considering the potential of this sector to contribute to greenhouse gas reduction while supporting ecosystem sustainability. There are a wide range of visualization technologies that have been applied to planning at a variety of scales, including but not limited to virtual reality, three-dimensional simulations, and animations (Bentrup and Wells 2005). Among these, PVZs are visualizations that are digitally created and can be printed or viewed online. They are appealing in an agricultural context in part because they can be used by agricultural advisors in the field.

Although there are many examples of investigations into visual perceptions of agricultural landscapes, as well as a robust body of literature concerning PVZs used to support climate change adaptation practices broadly, there is a lack of research on the efficacy of PVZs that depict agricultural sites that have implemented climate change adaptation practices. The exception to this is earlier work by our team that used focus groups to better understand the potential of PVZs for facilitating dialogue among farmers and agricultural advisors (Schattman et al. 2019). Farmers will likely need to respond to the effects of climate change through adoption of various climate adaptation practices (Niles et al. 2016; Walthall et al. 2012). Continual refinement of outreach and education on climate adaptation topics is needed, and PVZs should be evaluated for their utility in this context.

\section{a. Photovisualization in agriculture and climate change communication}

There are many different types of visualizations, and research pertaining to their efficacy as communication and outreach tools is well developed. This study focuses specifically on photovisualizations, also called landscape visualizations or photosimulations, which are computeraltered photographs depicting proposed planning, design, or management scenarios (Appleton and Lovett 2003; Lewis and Sheppard 2006). PVZs can be used as communication or educational tools to inform decision-making by individual clients, organizations, and communities, as they help to increase stakeholders' understanding of spatial components, aesthetics, cost, and ecological attributes of proposed changes, or alternative future scenarios (Sheppard 2005; Sheppard et al. 2011). They complement other forms of communication, such as written proposals or oral presentations, and have been shown to help people understand advanced planning concepts (Lewis and Sheppard 2006), which can be difficult to communicate to lay audiences. PVZ images have been found to support dialogue and decisionmaking among planners, designers, property owners, and other diverse audiences (Al-Kodmany 2002; Lewis and Sheppard 2006; Meitner et al. 2005; Tress and Tress 2003; Schattman et al. 2019).

PVZs are typically used in the fields of architectural design, landscape design, and urban planning (Lange et al. 2008; Lewis et al. 2012; Middel et al. 2009; Visscher et al. 2016). They have also been used for depiction of forest and parks management options (Bettigole et al. 2014; Junker and Buchecker 2008; Lange 2011). An emerging body of scholarship in recent years has applied PVZs in the context of agricultural land management. For example, Warren-Kretzschmar and Von Haaren (2014) report on the use of simulated PVZs in participatory planning processes at the farm scale, where views and aesthetics impact both land owners/private entities and the public. Wilhelm (2017) recently surveyed food systems stakeholders and the general public to compare preference rankings of different agricultural land uses in New Hampshire. Dockerty et al. (2012) used PVZs (bird's-eye views and on-the-ground perspectives) to survey public reaction to two different biomass crops over a seasonal timeframe. Lindemann-Matthies et al. (2010) explored perceptions of attractiveness and scenic beauty associated with varying intensities of management and levels of biodiversity among 16 different PVZs of agricultural landscapes in the Swiss Alps. Using a relatively early version of visualization technology, Appleton and Lovett (2003), explored the important question of appropriate levels of realism in PVZs themselves; they used PVZs of the rural English countryside and surveyed responses to varied modifications of different individual components of PVZs (such as foreground, background, ground plane). 
Visual images of climate change in the media have been shown to be influential over the cultural politics of climate change (O'Neill 2013), although not all types of climate change imagery affect viewers in the same way. For example, Leviston et al. (2014) found that images of natural disasters (i.e., brushfires, tidal waves, cyclones) provoked viewers to a greater degree than images of drought, and that viewers often associated climate change with images that were not relevant to their local environment (i.e., polar bears and icebergs). Meanwhile, PVZs that depict the local impacts of climate changes have been shown to be more resonant with viewers, eliciting discussion about climate change solutions (Nicholson-Cole 2005). In the context of adaptation planning and communication at a local level, PVZs have been used to generate discussions about how familiar and iconic locations will be impacted (Shaw et al. 2009), for example when seas level rise threatens coastal communities (Jude et al. 2006; Sheppard et al. 2008). Climate change-related PVZs that are perceived by viewers to be authentic and credible are associated with intentions to change personal behavior (Chapman et al. 2016).

\section{b. Agricultural best management practices in the context of climate change}

Best management practice (BMP) is a term often used to describe agricultural practices that have been tested and proven to limit nonpoint source pollution (Logan 1990). In recent years, this definition has been widely used to mean agricultural practices that have been verified to achieve a broad range of desired outcomes. BMPs can generate economic returns as well as improve soil and water quality, often over the long term (Howden et al. 2007), although farmers are not generally compensated for the full cost of implementation of these practices in the United States. In other words, BMPs are generally voluntary in the United States, although some federal and state programs have been designed to incentivize them. These programs vary widely among states. BMPs can also aim to enhance soil quality, increase vegetative cover, increase water quality, increase economic viability, reduce farm risk and vulnerability, adapt to uncertainty and extremes, and mitigate atmospheric $\mathrm{CO}_{2}$ (Helling et al. 2015).

The reasons why farmers choose to implement BMPs is an area of continuing investigation (Carlisle 2016; Prokopy et al. 2008, 2019). Various barriers to implementation can limit or prevent BMP adoption by farmers, and the factors that correlate with farmer adoption of BMPs are variable (Baumgart-Getz et al. 2012) and not universal (Knowler and Bradshaw 2007). Farmers' decision-making around BMPs is likely complicated by climate change. This is due to the degree of impact climate change is having and is projected to have on agricultural sectors (Hatfield et al. 2018; National Academies of Sciences Engineering and Medicine 2018), the time scale on which these changes are occurring (Naess 2013), and the multiple time scales on which many farmers are making management decisions (Risbey et al. 1999). Careful evaluation of BMPs that also serve as climate change adaptation practices is desirable.

To this end, some studies have probed farmer perceptions of climate-related risk, which is assumed to be a motivating factor for adoption of climate adaptation BMPs. For example, Schattman et al. (2016) have shown that farmers' perceptions of climate- and weatherrelated risk span ecological and economic concerns, and that adaptations taken to address these perceived risks are wide ranging. As it relates to climate change adaptation, Niles et al. (2015) found that farmers' willingness to adopt adaptation strategies was influenced by local-level limiting factors such as water or temperature impacts, showing the importance of geographic context and climate impacts for farmer adoption. Other work has reported that a farmer's own perceived capacity to adopt practices is critical both for intention and actual adoption of climate mitigation and adaptation practices (Niles et al. 2016), suggesting that understanding what a practice looks like may be important for farmers to believe they have the capacity to implement it. PVZs have the potential to aid Extension, policymakers, and others in efforts to encourage farmer adoption of BMPs that can support climate change adaptation. Considering this context, three research questions were developed:

1) How do the perspectives of farmers, agricultural advisors, and other agricultural stakeholders differ regarding the importance of climate change adaptation, and specifically the utility of four PVZs of BMPs in this context?

2) How do farmers, agricultural advisors, and other agricultural stakeholders weigh limiting factors associated with these climate adaptation BMPs?

3) Do PVZs have an effect on the willingness of farmers and agricultural advisors to consider implementing, adopting, or recommending a climate adaptation BMP?

\section{c. Research context}

This study was conducted in Vermont, a rural northeastern U.S. state with a strong agricultural history. In Vermont and the Northeast region generally, climate 
TABLE 1. Written descriptions that were included within survey instrument for each of four climate change best management practices, as presented to survey respondents.

\begin{tabular}{|c|c|}
\hline Practice & Description \\
\hline Riparian buffers & $\begin{array}{l}\text { Vegetated riparian buffers, typically } 25-50 \text { feet wide, can be used to control erosion of } \\
\text { stream banks. This riparian buffer is composed of a mix of native species that will help } \\
\text { the riverbank resist erosion and scouring due to high waters or overbank flooding. } \\
\text { It can also provide wildlife habitat along the river, and help shade and cool the river } \\
\text { for aquatic wildlife. Also shown in this image are live stakes-typically willow or } \\
\text { dogwood species-planted along the banks. Live stakes will grow so that their roots } \\
\text { spread, helping to reduce erosion on the stream banks during water level fluctuations. }\end{array}$ \\
\hline Drainage tile with constructed wetland & $\begin{array}{l}\text { Drainage tile alleviates flooding in this field and redirects excess water through a below- } \\
\text { surface pipe to a constructed wetland. The constructed wetland uses soils and plants to } \\
\text { filter and treat runoff water (removing excess nutrients, sediments, and other } \\
\text { pollutants) and improves wildlife habitat on the farm. }\end{array}$ \\
\hline Retention pond & $\begin{array}{l}\text { Retention ponds collect and store stormwater and agricultural runoff for subsequent } \\
\text { release, slowing runoff velocities and reducing erosion problems downstream. } \\
\text { Retention ponds typically have a permanent pool of water edged by natural pond } \\
\text { vegetation; they filter nutrients and sediments to improve water quality and also } \\
\text { provide wildlife habitat. }\end{array}$ \\
\hline Silvopasture & $\begin{array}{l}\text { Silvopasture refers to the cohabitation of pasture animals and harvestable trees. } \\
\text { Silvopasture can improve soil health, increase water infiltration, reduce erosion, } \\
\text { regulate microclimates, reduce weeds and pests, enhance tree growth, provide } \\
\text { windbreaks, reduce animal stress, and diversify production (i.e., timber, fruit, nuts). } \\
\text { The trees are planted in rows to maintain pasture and space for machinery. Movable } \\
\text { fencing is shown in the forefront of the image; it is used for rotational grazing where } \\
\text { livestock are moved across fields to spread out impacts and improve soil fertility, plant } \\
\text { health, and rainfall infiltration. }\end{array}$ \\
\hline
\end{tabular}

change impacts that will have the greatest impact on agriculture include increased precipitation intensity, increased summer temperatures and periods of drought, and increased variability in shoulder-season temperatures (Dupigny-Giroux et al. 2018; Gowda et al. 2018, Wolfe et al. 2018). In recent years, extreme events such as Tropical Storm Irene (2011) have affected Vermont's agricultural sectors and catalyzed new dialogue about climate change adaptation (Coleman et al. 2017; Schattman et al. 2016). Producers in this area have already begun to adapt to changing weather patterns, but there are many more who have yet to explore potentially useful climate adaptation BMPs.

\section{Methods}

\section{a. Development of photovisualizations and survey instrument}

To address our research questions and create PVZs that would resonate with agricultural producers and advisors in this temperate region, the team selected BMPs that reflected Vermont's primary agricultural activities, namely dairy and diversified farming systems (USDA-NASS 2013). When selecting the BMPs for our study, we drew from a list of approximately 22 BMPs with the potential to help farmers adapt to climate change. This list was developed through the Vermont Agricultural Resilience in a Changing Climate initiative in collaboration with Vermont farmers (Schattman et al. 2014). The final BMPs included in the PVZ investigation were riparian buffers, drainage tiles with constructed wetlands, retention ponds, and silvopasture. Selection of these particular practices was based on the ability of the BMPs to address the climate-related changes already evident in the region, specifically changing precipitation and temperature patterns. Critically, these practices had spatial attributes that allowed them to be depicted visually. Written descriptions of the BMPs and their potential advantages in a northeastern U.S. context can be found in Table 1.

For each BMP, an image pair was developed that portrayed the existing site conditions on a Vermont farm accompanied by a realistic, computerized photosimulation depicting implementation of the BMP. Adobe Photoshop from the Adobe CS5 software was used for this purpose. Paired existing-conditionPVZ images are depicted in Fig. 1.

An intercept survey was designed using the Dillman tailored design method (Dillman 2007). Although this reference is often used for mail and Internet surveys, it also provides excellent guidance on general survey development. Institutional Review Board approval was 

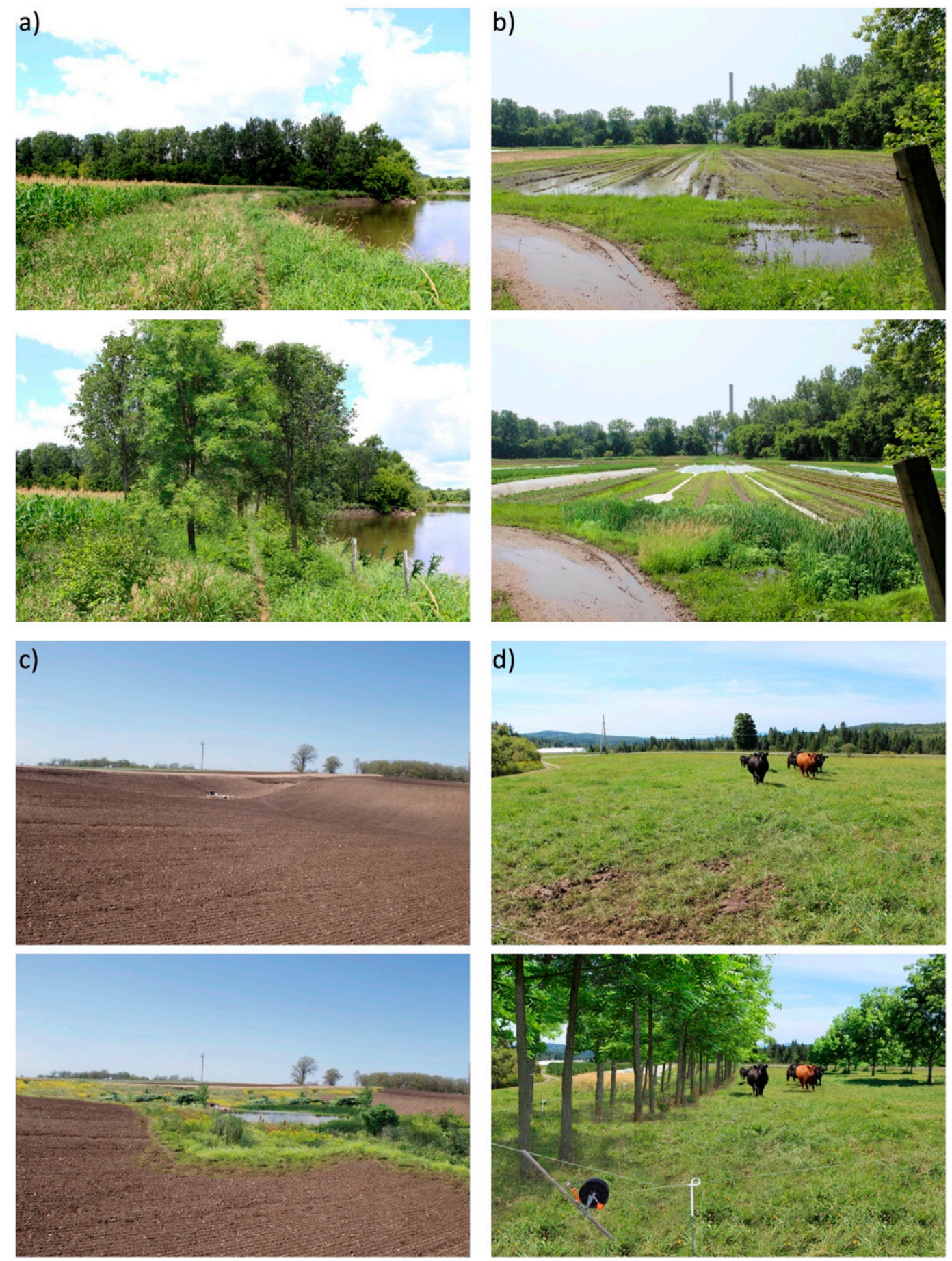

FIG. 1. Four "existing and proposed" PVZ posters displayed at the conference table where surveys were distributed and collected: (a) riparian buffers, (b) drainage tiles with constructed wetlands, (c) retention ponds, and (d) silvopasture.

obtained prior to survey deployment [Committee on Human Research in the Behavioral Sciences (CHRBS): B13-180]. The survey was reviewed and revised by several researchers with relevant expertise from outside the team prior to being finalized. The survey was designed in two parts, where participants would complete one section prior to viewing the PVZs, and the second section afterward. 


\section{b. Data collection and analysis}

Intercept surveys were conducted at six farmer conferences in Vermont between January and March 2015. The conferences attended for the project included the Northeast Organic Farming Association Winter Conference ( $n=65$ surveys collected), the Vermont Organic Dairy Producers Conference $(n=22)$, the Vermont Grazing and Livestock Conference $(n=18)$, the Vermont Grain Growers Conference $(n=10)$, the Vermont Dairy Producers Conference $(n=9)$, and the No-Till and Cover Crop Symposium $(n=9)$. The conferences were selected in order to reach diverse agricultural audiences, including both organic and conventional producers and a variety of farm types. Note that Vermont is among the top 10 states in the United States when it comes to both number of certified organic farms and acres used for production of certified organic agricultural products (USDA-NASS 2017). While we did not collect information from survey respondents that indicated whether their operations were certified as organic, it is likely that a notable proportion of our sample followed organic practices.

In all, 133 individuals participated in the survey across all conferences. At each conference, the research team displayed four posters depicting the paired images. The posters (dimensions: $61 \mathrm{~cm}$ wide $\times 91 \mathrm{~cm}$ long) were visible and intended to be viewed while participants completed the paper surveys. Participation was incentivized with maple candy. A full copy of the survey can be found in the online supplemental material ["Landscape Visualizations of Climate Change Best Management Practices (CCBMPs) SURVEY"].

The data collected in the survey included demographics, farm characteristics (for those respondents engaged in farming), perceptions of climate change, and reactions to the PVZs. Table 2 reports relevant variable names, questions, and scales that we utilized in our analyses. Prior to viewing the PVZs, several questions were asked to assess respondents' climate change perceptions. After respondents were shown the PVZs, they were asked questions about each specific practice, their perceptions about whether it was a useful practice to help with climate change adaptation, limiting factors for adoption, and whether the PVZs helped clarify their understanding of the BMP.

Survey results were analyzed for descriptive statistics in $\mathrm{R}$ version 3.5.2 ( $\mathrm{R}$ Core Team 2018). The demographic descriptions of our survey respondents are summarized in Table 3. To better answer our research questions, respondents were divided into three demographic groups: farmers (i.e., commercial farmers and homesteaders) $(n=72)$; advisors (i.e., Extension professionals, technical service providers) $(n=28)$; and others (i.e., researchers, university faculty or staff, students, or self-described "others" who attended agricultural conferences out of professional or personal interest) $(n=33)$. Multiple pairwise mean comparisons were used to test differences between these respondent types (Stoline 1981).

Five multivariate ordered logit models were developed to assess how different variables were related to potential adoption of the BMPs depicted in the PVZs. Ordered logit models are logistic regression models that use the mean of the binary response variable instead of the response variable itself. Multivariate models were developed in Stata (version 13). Four of these models were developed to analyze respondent perceptions of the utility of BMPs for climate change adaptation. Common independent variables were used in each model, specifically the limiting factors featured in Table 2 as well as several other factors. In addition, we incorporated dummy variables to categorize farmer and advisor respondents.

The fifth model assessed how, after viewing the PVZs, farmers' and advisors' willingness to consider adopting or recommending the BMPs changed. Because the dependent variable in this model (photo adopt BMP) was related to willingness to either adopt (for farmers) or recommend (for advisors) a practice, this model was restricted to those groups of respondents only. We included a number of variables that assessed general perceptions of climate change and PVZs (referred to in the survey as "photo-simulations"), irrespective of a specific practice. Since no respondents indicated a " 3 " in response to photo or reading (indicating that reading information was more useful) we created a new photo or reading variable (a dummy variable) for respondents who indicated that "seeing a photo-simulation image is more useful" as compared with being equally as useful as reading the information. See Table 2 for the variable overview. Variable names are consistently used in the model results.

Note that each of the BMPs selected for this study are well established as conservation practices, and that the value of PVZs in conservation and natural resource planning and policy has been previously established (Bentrup and Wells 2005). The overlap between conservation and climate adaptation is due to the multiple and overlapping benefits associated with these practices (e.g., improved soil health and water infiltration, reduced erosion and nutrient leaching). By framing these practices as climate adaptation practices, and by incorporating respondents' perceptions of climate change into our analysis, this research 
TABLE 2. Variable names, questions, and scales used in the models and statistical analysis.

\begin{tabular}{|c|c|c|}
\hline Variable & Question & Scale \\
\hline Adapt (practice name) & $\begin{array}{l}\text { (BMP name) is a useful practice to help } \\
\text { with climate change adaptation }\end{array}$ & $\begin{array}{l}1=\text { strongly disagree } 2=\text { disagree } \\
3=\text { neither agree nor disagree } 4=\text { agree } \\
5=\text { strongly agree }\end{array}$ \\
\hline Photo practice & $\begin{array}{l}\text { This photo-simulation clarifies my } \\
\text { understanding of what this best } \\
\text { management practice consists of }\end{array}$ & $\begin{array}{l}1=\text { strongly disagree } ;=\text { disagree; } \\
3=\text { neither agree nor disagree } 4=\text { agree } \\
5=\text { strongly agree }\end{array}$ \\
\hline Photo adapt & $\begin{array}{l}\text { Overall, do these photo-simulations help } \\
\text { you to envision what agricultural } \\
\text { adaptations to climate change might } \\
\text { look like in Vermont? }\end{array}$ & $1=$ no $; 2=$ a little bit $3=$ somewhat $4=$ yes \\
\hline Photo or reading & $\begin{array}{l}\text { Compare how useful seeing a photo- } \\
\text { simulation is vs reading the information }\end{array}$ & $\begin{array}{l}0=\text { seeing the image and reading the } \\
\text { information are equally useful; } 1=\text { seeing a }^{\text {a }} \\
\text { photo-simulation image is more useful }\end{array}$ \\
\hline Climate adaptation & $\begin{array}{l}\text { How important do you think it is for } \\
\text { Vermont farms to adapt to climate } \\
\text { change (things like flood prevention, } \\
\text { adjusting to changes in growing seasons, } \\
\text { and planning for more rain and/or more } \\
\text { drought at different times of year)? }\end{array}$ & $\begin{array}{l}1 \text { = Not important; } 2=\text { somewhat important; } \\
3 \text { = important; } 4=\text { very important } \\
\text { (included a "Not Sure" option, but it is not } \\
\text { included in the model analyses) }\end{array}$ \\
\hline Climate change knowledge & $\begin{array}{l}\text { How knowledgeable do you feel about } \\
\text { climate change as it pertains to } \\
\text { farming? }\end{array}$ & $\begin{array}{l}1 \text { = No knowledge; } 2=\text { a little knowledge; } \\
3=\text { some knowledge; } 4=\text { very } \\
\text { knowledgeable (included a "Not Sure" } \\
\text { option, but it is not included in the model } \\
\text { analyses) }\end{array}$ \\
\hline $\begin{array}{l}\text { Limiting factors: installation cost, } \\
\text { maintenance cost, time/labor for } \\
\text { installation, time/labor for } \\
\text { maintenance, aesthetic concerns, } \\
\text { technical assistance, additional } \\
\text { information, perception BMP effective, } \\
\text { and BMP relevant }\end{array}$ & $\begin{array}{l}\text { Rate the following potential factors } \\
\text { based on their capacity to limit the } \\
\text { implementation of (practice). Is this a } \\
\text { limiting factor? }\end{array}$ & $1=$ Yes $; 0.5=$ somewhat $0=$ no \\
\hline Photo adopt BMP & $\begin{array}{l}\text { Are you more likely to consider } \\
\text { implementing/recommending these } \\
\text { climate change best management } \\
\text { practices after seeing these photo- } \\
\text { simulations? }\end{array}$ & $\begin{aligned} 1=\text { No, not at all } ; 2 & =\text { not likely } ; 3=\text { maybe } ; \\
4 & =\text { very likely } ; 5=\text { definitely }\end{aligned}$ \\
\hline
\end{tabular}

\footnotetext{
${ }^{\text {a }}$ This response was originally coded as $1=$ seeing a photo-simulation image is more useful, $2=$ seeing the image and reading the information are equally useful, or 3 = reading information is more useful. However, there were no " 3 " responses, so the variable was recoded as a binary variable where equal usefulness $=0$ and the photosimulation image being more useful $=1$.
}

makes a unique contribution to our understanding of how PVZs can be used for climate adaptation in agricultural settings.

\section{Results}

\section{a. Climate change knowledge and perspectives on agricultural adaptation}

Among survey respondents, we found that advisors reported the highest mean self-perceived climate change knowledge as it pertained to farming (3.38), which was significantly $(p<0.05)$ different than farmers (2.98) and other respondents (2.88). When asked about whether it was important for Vermont farms to adapt to climate change (climate adaptation), $91.6 \%$
( $n=120)$ thought that it was either "important" or "very important." Respondents in the "other" category had the highest mean with regard to perceived importance of climate adaptation for Vermont farms (3.86), which was not significantly different than advisors (3.78) but was significantly different $(p<0.01)$ than farmers (3.47). Among farmer respondents, $47.2 \%$ were "very interested" in integrating climate adaptation into their farming practices $(n=34)$, and $33.3 \%$ had "some interest"' $(n=24)$. There was agreement among respondents that the four BMPs depicted in the PVZs were useful practices for climate change adaptation (adapt); mean responses for each BMP were as follows: riparian buffers (4.05), drainage tile with constructed wetland (4.01), retention ponds (4.22), and silvopasture (4.01). 
TABLE 3. Survey respondent demographics $(n=133)$

\begin{tabular}{|c|c|}
\hline & $N(\%)$ \\
\hline Farmers $^{\mathrm{a}}$ & $72(54 \%)$ \\
\hline Landowners & $53(75.7 \%)$ \\
\hline Rented or leased land & $25(35.7 \%)$ \\
\hline Advisors $^{\mathrm{b}}$ & $28(21 \%)$ \\
\hline Others $^{\mathrm{c}}$ & $33(25 \%)$ \\
\hline \multicolumn{2}{|l|}{ Farm types $^{\mathrm{a}}$} \\
\hline Dairy & $26(37.1 \%)$ \\
\hline Livestock & $25(25.7 \%)$ \\
\hline Vegetable & $21(30 \%)$ \\
\hline Orchard & $5(7.1 \%)$ \\
\hline Berry & $5(7.1 \%)$ \\
\hline Other $^{\mathrm{d}}$ & $14(20 \%)$ \\
\hline \multicolumn{2}{|l|}{ Geography } \\
\hline Vermont & $48(36.1 \%)$ \\
\hline $\begin{array}{l}\text { New England or New York (excluding } \\
\text { Vermont) }\end{array}$ & $1(0.8 \%)$ \\
\hline Other U.S. states ${ }^{\mathrm{e}}$ & $6(4.5 \%)$ \\
\hline Canada & $1(0.8 \%)$ \\
\hline
\end{tabular}

${ }^{\mathrm{a}}$ Farm types and land access strategy were not mutually exclusive options.

${ }^{\mathrm{b}}$ Extension professionals, technical service providers, or others who deliver direct services to farmers.

${ }^{c}$ Researchers, university faculty or staff, students, or self-described "others" who attended agricultural conferences out of professional or personal interest.

${ }^{\mathrm{d}}$ Other products included grain, hay, faro, flowers, forest products, bees, pasture/grassland, wheat, grapes, and pawpaws.

${ }^{\mathrm{e}}$ Other states included Illinois, Colorado, Maryland, Pennsylvania, and Virginia.

\section{b. Comparative limiting factors in practice adoption}

When presented with a list of potential limiting factors that could inhibit their adoption of a BMP (for farmers) or their willingness to recommend a BMP (for advisors), the cost of installing a BMP was cited as an important limiting factor for riparian buffers (mean $0.58)$, drainage tile with constructed wetland (0.24), retention ponds (0.41), and silvopasture (0.70). The time and labor required to install and maintain the BMPs was also listed as an important limiting factor, as was the need for technical assistance and/or additional information. Among all four BMPs, the least identified limiting factor was aesthetic concerns.

In general, we found little evidence of consistent limiting factors that were statistically significant between farmers, advisors, and others related to the four climate adaptation practices. However, there were some notable differences. Specifically, farmers were more likely $(p<0.10)$ to believe that riparian buffers would work effectively. Farmers had a lower mean perception that time and labor for maintenance of drainage tiles with constructed wetlands would be a limiting factor for adoption $(p<0.05)$. Advisors had an overall higher perception that the cost of installation would be a limiting factor for adopting retention ponds as compared to other respondents $(p<0.05)$. Farmers had a greater concern for aesthetics as a limiting factor for retention ponds as compared with other respondents $(p<0.10)$. Farmers, more than advisors (mean $0.49 ; p<0.01$ ) or others (mean 0.56; $p<0.05$ ), also felt on average they needed additional information to assess retention ponds (0.76).

Perhaps as a result of these differences, farmers had a statistically lower overall mean perception that BMPs would be effective (mean 0.78) as compared to others (mean 0.92; $p<0.05$ ) and advisors (mean $0.88 ; p<0.10$ ). Farmers felt on average they needed additional technical assistance as related to silvopasture (mean 0.63) as compared with advisors (mean 0.45; $p<0.05$ ). Advisors also felt on average that they did not need additional information related to silvopasture (mean 0.42) as compared with farmers (mean 0.65; $p<0.05$ ) and others (mean $0.63 ; p<0.05$ ). Farmers had lower confidence in the ability of silvopasture to work (mean 0.69) than did advisors (mean 0.86; $p<0.01$ ) and others (mean $0.83 ; p<0.05$ ). Consistently, and not surprisingly, farmers had a higher perception overall that the adaptation practices were relevant to them as compared to advisors (drainage tiles with constructed wetlands, retention ponds) and others (retention ponds, silvopasture $)(p<0.05)$.

\section{c. The effect of photovisualization on adaptation perspectives}

Respondents also reported that the PVZ improved their understanding (photo practice) of riparian buffers (mean 4.03), drainage tile with constructed wetland (3.85), retention ponds (4.07), and silvopasture (4.09). There were differences among the respondent groups regarding how well the PVZs improved understanding of the BMPs. Those respondents who fell into the others category reported a significantly higher $(p<0.05)$ mean (4.00) as compared with farmers (3.80) with regard to the overall clarifying ability of PVZs for understanding these practices.

Most respondents $(87 \%, n=107)$ reported that the PVZs helped them to envision what climate adaptation BMPs might look like in Vermont (photo adapt; mean 3.85). While significant differences between respondent groups were not common, there were a few notable exceptions. Specifically, respondents in the others category were more likely to report that PVZs that depicted drainage tile with constructed wetland improved their ability to envision that BMP (4.21), followed by farmers (4.04; statistically different than advisors at $p<0.10$ ), and advisors (3.67; statistically different than other 
TABLE 4. Multivariate regression model results (coefficients and $p$ values) for climate adaptation practice perception [referred to as adapt (practice name) in Table 2]. Statistically significant results $(p<0.05)$ are italicized for clarity.

\begin{tabular}{|c|c|c|c|c|c|c|c|c|}
\hline Variable & Riparian & $p$ & Drainage & $p$ & Ponds & $p$ & Silvopasture & $p$ \\
\hline Photo riparian & 0.770 & 0.009 & 1.370 & 0.000 & 1.140 & 0.001 & 1.262 & 0.000 \\
\hline Installation cost & -0.940 & 0.281 & -1.633 & 0.169 & 1.854 & 0.187 & 0.625 & 0.564 \\
\hline Maintenance cost & 0.458 & 0.573 & 0.800 & 0.423 & -0.724 & 0.450 & -1.206 & 0.304 \\
\hline Time/labor for installation & 0.958 & 0.202 & -0.556 & 0.651 & -0.720 & 0.645 & -1.095 & 0.283 \\
\hline Time/labor for maintenance & -0.016 & 0.986 & -0.989 & 0.366 & 0.181 & 0.849 & 0.965 & 0.383 \\
\hline Aesthetic concerns & -0.812 & 0.411 & 0.241 & 0.786 & -0.502 & 0.608 & -0.837 & 0.345 \\
\hline Technical assistance & 0.273 & 0.731 & 0.556 & 0.479 & -0.487 & 0.571 & 0.570 & 0.584 \\
\hline Additional information & 0.229 & 0.797 & 0.283 & 0.708 & 1.040 & 0.202 & -0.890 & 0.398 \\
\hline BMP work & 0.347 & 0.786 & 2.251 & 0.031 & 2.144 & 0.095 & 3.616 & 0.003 \\
\hline BMP relevant & -0.491 & 0.458 & 0.751 & 0.300 & -0.100 & 0.882 & -0.964 & 0.227 \\
\hline Photo or reading & 0.865 & 0.060 & 0.431 & 0.342 & -0.729 & 0.138 & -0.201 & 0.678 \\
\hline Climate adaptation & 0.731 & 0.035 & 1.239 & 0.002 & 1.593 & 0.001 & 1.046 & 0.021 \\
\hline Climate knowledge & 0.737 & 0.015 & -0.012 & 0.971 & 0.286 & 0.423 & -0.311 & 0.384 \\
\hline Farm & -0.132 & 0.814 & -0.831 & 0.164 & 0.091 & 0.880 & 0.741 & 0.277 \\
\hline Advisor & -0.196 & 0.763 & -1.853 & 0.012 & -0.538 & 0.488 & 0.220 & 0.765 \\
\hline$N$ & 92 & & 99 & & 98 & & 92 & \\
\hline$R^{2}$ & 0.14 & & 0.31 & & 0.33 & & 0.34 & \\
\hline
\end{tabular}

respondents at $p<0.05)$. Other respondents and farmers, as compared with advisors, also had higher means related to both the potential of silvopasture for climate change adaptation and the role of PVZs in clarifying understanding of the BMPs. (These results are reported in greater detail in the online supplemental materials as Tables SM1-SM4.)

When asked if they were more likely to consider implementing or recommending the climate adaptation BMPs after seeing the PVZs (photo adopt BMP), $32 \%$ of respondents $(n=39)$ chose that they were "very likely" to do so and $18 \%(n=22)$ reported that they "definitely" would do so. A minority $4.1 \%(n=5)$ reported that they were unlikely to consider implementing or recommending the BMP after seeing the PVZ. This indicates that PVZs are related to potential adoption of climate adaptation BMPs among agricultural audiences (mean response 3.74). When respondents were asked to compare the utility of a PVZ versus reading information about a practice (photo or reading), the majority of respondents $(57.4 \% ; n=70)$ reported that the PVZs are more useful, while $42.6 \%(n=52)$ indicated that seeing the image and reading the information were equally useful. No respondents indicated that reading information alone was preferred over the other two options.

Four separate multivariate regression models that assessed factors associated with perceptions of BMPs revealed a consistent trend: belief that the PVZs improve understanding of a BMP (photo practice) was significantly $(p<0.05)$ associated with increased agreement that a practice is useful for climate change adaptation (adapt). Relatedly, respondents felt that
Vermont farms should adapt to climate change (climate adaptation), which was statistically significant across models. This suggests that respondents who saw climate change adaptation as necessary were more likely to intend to adopt the BMPs. (See Table 4 for model summaries, and Tables SM1-SM4 in the online supplemental materials for full model results.)

There were no other consistently similar results across the models; however, the models showed interesting results pertinent to individual BMPs. Climate knowledge was significant for respondents' sense of utility of riparian buffers $(b=0.737 ; p=0.015)$, suggesting that respondents with greater perceived climate knowledge (climate change knowledge) were more likely to agree the practice was a useful climate adaptation strategy (adapt). For drainage tiles with constructed wetlands, respondents' perceptions regarding whether the BMP would work ( $b=2.251 ; p=0.031)$ was positively associated with the practice being seen as a climate adaptation strategy. Conversely, a subset of respondents (advisors) were less likely to believe drainage tiles with constructed wetlands would be a useful climate adaptation strategy in comparison with other practices $(b=-1.853 ; p=0.012)$. Belief that silvopasture would be generally effective as a BMP $(b=3.616 ; p=0.003)$ was positively associated with belief that practice was a useful adaptation strategy. Models demonstrated $R^{2}$ values ranging from 0.14 (riparian buffers) to 0.34 (silvopasture).

A fifth model assessed factors correlated with whether respondents were more likely to adopt a practice (photo adopt BMP) after viewing the PVZ of that practice. We find two factors correlated with adoption likelihood. 
TABLE 5. Multivariate regression model of PVZ effect on adoption likelihood (photo adopt BMP). Statistically significant results are italicized.

\begin{tabular}{|c|c|c|c|c|c|c|}
\hline Variable & Coef & Std error & $T$ value & $P$ value & \multicolumn{2}{|c|}{ Confidence interval } \\
\hline Photo adapt & 1.321 & 0.685 & 1.930 & 0.054 & -0.021 & 2.663 \\
\hline Photo or reading & 1.159 & 0.516 & 2.240 & 0.025 & 0.147 & 2.171 \\
\hline Climate adaptation & 1.492 & 0.443 & 3.370 & 0.001 & 0.625 & 2.360 \\
\hline Climate knowledge & -0.114 & 0.379 & -0.300 & 0.763 & -0.856 & 0.628 \\
\hline Farm & -1.006 & 0.848 & -1.190 & 0.235 & -2.667 & 0.655 \\
\hline Advisor & -0.708 & 1.378 & -0.510 & 0.607 & -3.408 & 1.992 \\
\hline Crop & 0.631 & 0.541 & 1.170 & 0.244 & -0.429 & 1.691 \\
\hline $\begin{array}{l}\text { Animal } \\
n=68 \text {; pseudo } R^{2}=0.21\end{array}$ & -1.096 & 0.578 & -1.890 & 0.058 & -2.229 & 0.038 \\
\hline
\end{tabular}

First, we find a positive correlation between adoption likelihood and seeing the PVZ as compared with reading the text accompanying the photosimulations. This suggests that people who thought seeing the PVZs was more useful than reading the text alone were more likely to say they would adopt the practices $(b=1.159 ; p=0.025)$. Second, we find that those that believe it is important for Vermont farms to adapt to climate change are more likely to consider implementing the practice after viewing the photosimulations $(b=$ $1.492 ; p=0.001$ ). Overall $R^{2}$ values indicate the model explains $21 \%$ of the variability in adoption likelihood (Table 5).

\section{Discussion}

Several findings from the analysis above inform broader conversations about climate change adaptation on farms, communication of different BMPs' visual and spatial features, and barriers to BMP implementation. Regarding climate change knowledge, the analysis indicated that agricultural advisors were significantly more likely than farmers to perceive having knowledge about climate change as it pertains to farming. However, model results showed that perceived knowledge appears to have no statistical significance in terms of likelihood of adopting or recommending one or more of the four identified BMPs. This indicates disconnection between having and applying knowledge, potentially due to a variety of reasons. Possibilities noted in prior studies include variation in knowledge and expertise based on advisors' professional roles, their level of confidence discussing climate change, or the perception that clients prefer alternative nomenclature. As Haigh et al. (2015) showed in their study of agricultural advisors in the midwestern United States, agricultural financial advisors are reluctant to discuss climate-related risk, while those who offered advice related to production or conservation issues are more willing to do so.
Monroe et al. (2015) found that advisors in the southeastern United States did not want to, or did not feel able to, provide their clients with information related to climate risk. Niles et al. (2016) report that climate change knowledge correlated with intention to adopt adaptation practices, but not actual adoption. Meanwhile, in a national study of U.S. Department of Agriculture (USDA) Farm Service Agency employees, Schattman et al. (2018) found that what an agricultural service provider believes about climate change is not strongly correlated to the intention of that provider to use climate and weather information in their professional services; rather, perceptions of weather-related risk and personal observations of weather variability were stronger predictors of intention to integrate climate and weather information into future service provision activities.

Results from the PVZ survey also suggest another notable result. Farmer respondents perceived that climate change adaptation in general was important or very important $(86 \%)$ whereas interest in adoption of climate change adaptation practices on one's own farm was slightly lower (47\% very interested, 33\% somewhat interested). This contrasts with the perspective from survey respondents in the "other" category, who were more likely than the advisors or farmers to say that Vermont farms should adapt to climate change. It should be noted that the likelihood of a large number of certified organic producers among our survey respondents may influence these results, although our survey did not document the exact percentage of these producers in the sample. It has been shown that organic farmers are sometimes more likely to believe in climate change (Niles et al. 2013). With this in mind, these results may reflect a broader societal phenomenon where individuals report that climate change is a problem and that adaptation is important (indicating preferences for what "should" be done), but are less likely to be personally motivated to be proactive in the face of threats from climate change (Leiserowitz et al. 2015). 

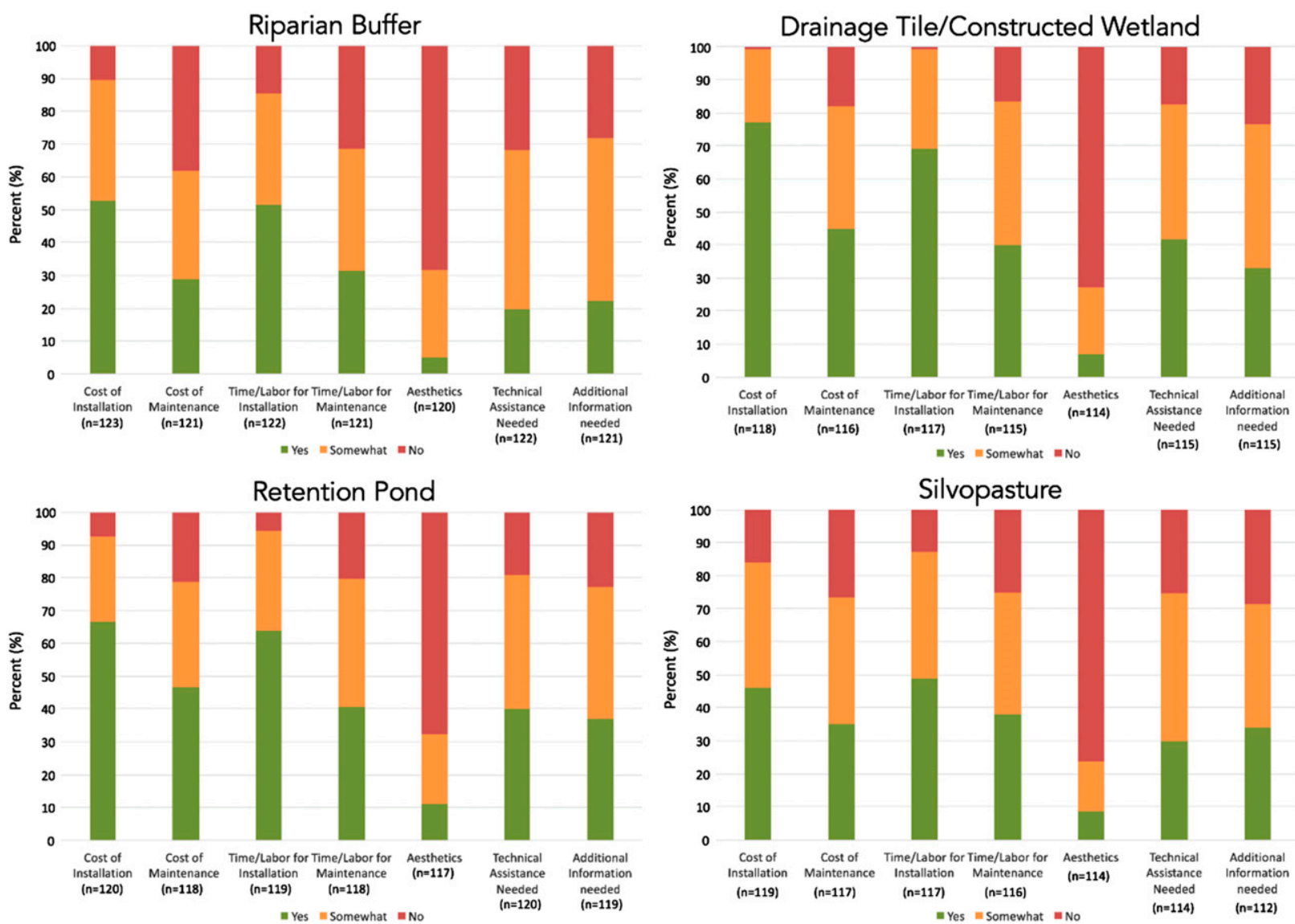

FIG. 2. Limiting factors associated with implementation of four BMPs are shown on the $x$ axis. Percent of respondents indicating whether a particular factor was limiting is shown on the $y$ axis. The number of respondents $n$ making up the $100 \%$ on the $y$ axis differed among survey questions, ranging from 112 to 123 respondents.

Several studies have attempted to explain this or similar disconnections. For example, Akerlof et al. (2013) have suggested that individual perceptions of risk associated with climate change are likely the result of personal experience with negative events, vicarious events (such as those experienced by friends and family, or learned about through news stories and other media), and societal construction (as informed by cultural worldviews, political affiliations, etc.). In other words, those who are aware of the threats from climate change but are not personally responsible for implementing adaptation activities or shouldering associated risks may more readily prescribe their use. In this instance, the "other" category of survey respondents would experience little direct burden of farmers adapting to climate change. Meanwhile, as shown in Table 4, the stated need for climate adaptation was an important predictor for likelihood of adoption. However, a thorough investigation into whether individuals actually would implement the BMPs, or where climate change falls in farmers' lists of priorities, is outside the scope of our study.
Across the four climate adaptation BMPs represented in the PVZs and evaluated in this survey, cost and time/labor for installation were consistently indicated as limiting factors for implementation (Fig. 2). This supports the findings of Helling et al. (2015) that the balance between economic risk and profitability is an important factor that farmers consider when weighing whether to implement an on-farm practice. While farmer motivations for adopting conservation practices have been shown to be diverse (Greiner et al. 2009), farmers are likely to be reluctant to adopt practices that potentially undermine the financial viability of their business. In our research, we also found that concerns about initial implementation of the BMPs were followed closely by concerns about cost of and time/labor for maintenance of the BMPs. This suggests a need for assistance in not only the establishment of BMPs on agricultural land, but also in their ongoing maintenance. Notably, this study only examined possible limiting factors for implementation of four BMPs. More research in varying agricultural settings may yield different limitations; as 
shown by Niles et al. (2015), the limiting factors of a given region will influence adoption. Additionally, there are likely limiting factors associated with ongoing maintenance of BMPs that should be further explored.

The results of this analysis strongly suggest that PVZs, currently underutilized in the context of agricultural climate adaptation outreach, are a useful education tool for encouraging agricultural adaptation practices. Our models suggest that PVZs would be most useful when working with a subset of agricultural stakeholders. Specifically, individuals who prefer PVZs to text as a way of learning about BMPs are more likely to adopt or recommend a practice (photo adopt BMP) after viewing the PVZ of that practice. Prior research on the efficacy of PVZs as education tools, while not conducted specifically with agricultural audiences, should also be taken into consideration. Some of this research has suggested that, to be most effective, PVZs should be combined with other communication forms during the planning process (Middel et al. 2009; Neto 2006), and that PVZs are more effective for decision-making when they are realistic and depict familiar (local) landscape contexts (Sheppard et al. 2011). While the value of imagery and visualizations to overall comprehension relates to an ongoing debate about different preferred and effective modes of learning that is outside of the scope of this paper (e.g., Fleming 2001; Leite et al. 2010; Willingham et al. 2015), our research nonetheless suggests that the efficacy of outreach materials can be enhanced by inclusion of visual media.

Further research is needed to parse out the tendencies of farmers who would naturally pursue climate adaptation practices (with little or no need for either PVZs or written descriptions) versus those who might learn useful information from exposure to PVZs as stand-alone objects or in combination with text or support from agricultural advisors. Additionally, we also note that one of our PVZs (constructed wetlands and drainage tiles) is actually two different practices that we combined into a single image, which may have obscured results pertinent to the individual BMPs.

While this study was constrained by a limited number of BMPs included, survey participants engaged in rich conversations about critical factors related to the BMPs (including regulations, costs, challenges associated with implementation, etc.). This observation corroborates prior studies that show the ability of PVZs to stimulate critical discussion that informs decision-making (Warren-Kretzschmar and Von Haaren 2014; Schattman et al. 2019). Our findings suggest that PVZs used in this context could be a beneficial complement to agriculture outreach and program implementation. To be most effective, PVZs should be created that accurately reflect the ecological and cultural context in which desired adaptation and mitigation activities would be applied (Sheppard et al. 2011). Future research may also benefit from looking beyond static PVZ imagery to 3D and virtual visualization techniques; Lovett et al. (2015) nicely summarize the comparative benefits and utility of various visualization products and technologies in the context of improving realism of imagery and enhancing participatory processes.

The implication of these findings extends beyond local adaptation to climate change. Discussions of this type, which encompass the inherent tradeoffs associated with climate adaptation BMPs, resonates with the broader global conversation about climate change adaptation and mitigation in agriculture. Potentially, PVZs can be applied in a way that contributes to the necessary conversations about the tradeoffs of different mitigation and adaptation actions among agricultural stakeholders, not only within agriculture, but between sectors.

\section{Conclusions}

Survey respondents (including farmers, agricultural advisors, and other agricultural stakeholders) reported that 1) the PVZs clarified their understanding of BMPs and 2) the suite of PVZs presented helped them to envision climate change adaptation more clearly. Viewing PVZs was associated with an increased interest in implementing or recommending a BMP among those who already believed climate change adaptation was important, and among those who preferred learning about BMPs through visual media (as opposed to textual explanations of the practice). This research shows that PVZs, while currently underutilized, have potential to enhance stakeholder outreach, engagement, and decision-making about agricultural adaptation to climate change. It should be acknowledged that PVZs address only some limitations to BMP implementation. Other barriers include availability of time and money, access to technical assistance, tacit knowledge, and perceived relevance. Each of these must be addressed (or overcome) to realize the full potential by farms for increasing resilience to climate change.

In summary, PVZs could prospectively play a key role in both the development of educational materials and dissemination of information related to new types of funding mechanisms for agricultural climate adaptation via national and local government, nonprofit, and private institutions. Future research could explore the use of PVZs in stakeholder outreach, PVZs that depict BMPs over the course of different seasons and weather events, a broader suite of potential climate adaptation BMPs, the relationship between agricultural advisors' 
knowledge of climate change adaptation and the recommendations they make, as well as the connections between farmers' intention to adopt and actual adoption of BMPs.

Acknowledgments. This research was supported by the USDA National Institute of Food and Agriculture, Hatch project 231242 and the USDA Northeast Climate Hub. We also thank Tom Schmidt, Ernesto Méndez, Juan Alvez, Kate Elmer, Debra Heleba, Joshua Faulkner, Susan Brouillette, Heather Darby, Gavin Zeitz, Chelsea Gieryic, Kate Odell, Jenn Colby, Reg Chaput, Ted Foster, Donna Brown, Kirsten Workman, and Meg Klepack for contributing to this research. The University of Vermont (UVM) Center for Sustainable Agriculture, Vermont Northeast Organic Farming Association (NOFA-VT), Vermont Dairy Producers Association, and UVM Extension hosted the various conferences. Thank yous are extended to all of the Vermont farmers who allowed us to take photographs on their land.

\section{REFERENCES}

Akerlof, K., E. W. Maibach, D. Fitzgerald, A. Y. Cedeno, and A. Neuman, 2013: Do people "personally experience" global warming, and if so how, and does it matter? Global Environ. Change, 23, 81-91, https://doi.org/10.1016/ j.gloenvcha.2012.07.006.

Al-Kodmany, K., 2002: Visualization tools and methods in community planning: From freehand sketches to virtual reality. J Plann. Lit., 17, 189-211, https://doi.org/10.1177/088541202762475946.

Appleton, K., and A. Lovett, 2003: GIS-based visualization of rural landscapes: Defining "sufficient" realism for environmental decision-making. Landscape Urban Plann., 65, 117-131, https://doi.org/10.1016/S0169-2046(02)00245-1.

Baumgart-Getz, A., L. S. Prokopy, and K. Floress, 2012: Why farmers adopt best management practice in the United States: A meta-analysis of the adoption literature. J. Environ. Manage., 96,17-25, https://doi.org/10.1016/j.jenvman.2011.10.006.

Bentrup, G., and G. Wells, 2005: A visual simulation of a proposed stream corridor restoration project. J. Soil Water Conserv., 60, 144-149.

Bettigole, C. A., T. M. Donovan, R. Manning, and J. Austin, 2014: Normative standards for land use in Vermont: Implications for biodiversity. Biol. Conserv., 169, 392-400, https://doi.org/ 10.1016/j.biocon.2013.07.009.

Carlisle, L., 2016: Factors influencing farmer adoption of soil health practices in the United States: A narrative review. Agroecol. Sustainable Food Syst., 40, 583-613, https://doi.org/10.1080/ 21683565.2016.1156596.

Chapman, D., A. Corner, R. Webster, and E. Markowitz, 2016: Climate visuals: A mixed methods investigation of public perceptions of climate images in three countries. Global Environ. Change, 41, 172-182, https://doi.org/10.1016/ j.gloenvcha.2016.10.003.

Coleman, S., S. Hurley, C. Koliba, and A. Zia, 2017: Crowdsourced Delphis: Designing solutions to complex environmental problems with broad stakeholder participation.
Global Environ. Change, 45, 111-123, https://doi.org/ 10.1016/j.gloenvcha.2017.05.005.

Dillman, D. A., 2007: Mail and Internet Surveys: The Tailored Design Method. John Wiley and Sons, 523 pp.

Dockerty, T., K. Appleton, and A. Lovett, 2012: Public opinion on energy crops in the landscape: Considerations for the expansion of renewable energy from biomass. $J$ Environ Plann. Manage., 55, 1134-1158, https://doi.org/10.1080/ 09640568.2011.636966.

Dupigny-Giroux, L., and Coauthors, 2018: Northeast. Impacts, Risks, and Adaptation in the United States, Vol. II, The Fourth National Climate Assessment, U.S. Global Change Research Program, https://doi.org/10.7930/NCA4.2018.CH18.

Fleming, N. D., 2001: Teaching and Learning Styles: VARK Strategies. IGI Global, $128 \mathrm{pp}$.

Gowda, P., J. L. Steiner, T. Farrigan, M. A. Grusak, and M. Boggess, 2018: Agriculture and rural communities. Impacts, Risks, and Adaptation in the United States, Vol. II, The Fourth National Climate Assessment, U.S. Global Change Research Program, https://doi.org/10.7930/NCA4.2018.CH10.

Greiner, R., L. Patterson, and O. Miller, 2009: Motivations, risk perceptions and adoption of conservation practices by farmers. Agric. Syst., 99, 86-104, https://doi.org/10.1016/ j.agsy.2008.10.003.

Haigh, T., L. W. Morton, M. C. Lemos, C. Knutson, L. S. Prokopy, Y. J. Lo, and J. Angel, 2015: Agricultural advisors as climate information intermediaries: Exploring differences in capacity to communicate climate. Wea. Climate Soc., 7, 83-93, https:// doi.org/10.1175/WCAS-D-14-00015.1.

Hatfield, J. L., and Coauthors, 2018: Indicators of climate change in agricultural systems. Climatic Change, https://doi.org/10.1007/ s10584-018-2222-2, in press.

Helling, A., D. Conner, S. Heiss, and L. Berlin, 2015: Economic analysis of climate change best management practices in Vermont agriculture. Agriculture, 5, 879-900, https://doi.org/ 10.3390/agriculture5030879.

Howden, S. M., J. Soussana, F. N. Tubiello, N. Chhetri, M. Dunlop, and H. Meinke, 2007: Adapting agriculture to climate change. Proc. Natl. Acad. Sci. USA, 104, 19691-19696, https://doi.org/ 10.1073/pnas.0701890104.

Jude, S., A. P. Jones, J. E. Andrews, and I. J. Bateman, 2006: Visualisation for participatory coastal zone management: A case study of the Norfolk Coast, England. J. Coast. Res., 226, 1527-1538, https://doi.org/10.2112/04-0294.1.

Junker, B., and M. Buchecker, 2008: Aesthetic preferences versus ecological objectives in river restorations. Landscape Urban Plann., 85, 141-154, https://doi.org/10.1016/ j.landurbplan.2007.11.002.

Knowler, D., and B. Bradshaw, 2007: Farmers' adoption of conservation agriculture: A review and synthesis of recent research. Food Policy, 32, 25-48, https://doi.org/10.1016/ j.foodpol.2006.01.003.

Lange, E., 2011: 99 volumes later: We can visualise. Now what? Landscape and Urban Plann., 100, 403-406, https://doi.org/ 10.1016/j.landurbplan.2011.02.016.

, S. Hehl-Lange, and M. J. Brewer, 2008: Scenario-visualization for the assessment of perceived green space qualities at the urban-rural fringe. J. Environ. Manage., 89, 245-256, https:// doi.org/10.1016/j.jenvman.2007.01.061.

Leiserowitz, A., E. Maibach, C. Roser-Renouf, G. Feinberg, and S. Rosenthal, 2015: Climate change in the American mind: October 2015. Yale Program on Climate Change Communication and George Mason University Center for 
Climate Change Communication Rep., 45 pp., https:// www.climatechangecommunication.org/all/october-2015climate-change-american-mind/.

Leite, W. L., M. Svinicki, and Y. Shi, 2010: Attempted validation of the scores of the VARK: Learning styles inventory with multitrait-multimethod confirmatory factor analysis models. Educ. Psychol. Meas., 70, 323-339, https://doi.org/10.1177/ 0013164409344507.

Leviston, Z., J. Price, and B. Bishop, 2014: Imaging in climate change: The role of implicit association and affective psychological distancing in climate responses. Eur. J. Soc. Psychol., 44, 441-454, https://doi.org/10.1002/ejsp.2050.

Lewis, J. L., and S. R. J. Sheppard, 2006: Culture and communication: Can landscape visualization improve forest management consultation with indigenous communities? Landscape Urban Plann., 77, 291-313, https://doi.org/ 10.1016/j.landurbplan.2005.04.004.

_ J. M. Casello, and M. Groulx, 2012: Effective environmental visualization for urban planning and design: Interdisciplinary reflections on a rapidly evolving technology. J. Urban Technol., 19, 85-106, https://doi.org/10.1080/10630732.2012.673057.

Lindemann-Matthies, P., R. Briegel, B. Schüpbach, and X. Junge, 2010: Aesthetic preference for a Swiss alpine landscape: The impact of different agricultural land-use with different biodiversity. Landsc. Urban Plan., 98, 99-109, https://doi.org/ 10.1016/j.landurbplan.2010.07.015.

Logan, T. J., 1990: Agricultural best management practices and groundwater protection. J. Soil Water Conserv., 45, 201-206.

Lovett, A., K. Appleton, B. Warren-Kretzschmar, and C. Von Haaren, 2015: Using 3D visualization methods in landscape planning: An evaluation of options and practical issues. Landsc. Urban Plan., 142, 85-94, https://doi.org/10.1016/ j.landurbplan.2015.02.021.

Meitner, M. J., S. R. J. Sheppard, D. Cavens, R. Gandy, P. Picard, H. Harshaw, and D. Harrison, 2005: The multiple roles of environmental data visualization in evaluating alternative forest management strategies. Comput. Electron. Agric. 49, 192-205, https://doi.org/10.1016/ j.compag.2005.03.002.

Middel, A., S. Guhathakurta, H. Hagen, and P.-S. Olech, and F. Höpel, 2009: Visualizing future 3-dimensional neighborhoods in Phoenix: An application incorporating empirical methods with computational graphics. Virtual Geographic Environments, M. Batty and H. Lin, Eds., Science Press, 87-102.

Monroe, M. C., R. R. Plate, D. C. Adams, and D. J. Wojcik, 2015: Harnessing homophily to improve climate change education. Environ. Educ. Res., 21, 221-238, https://doi.org/10.1080/ 13504622.2014.910497.

Naess, L. O., 2013: The role of local knowledge in adaptation to climate change. Wiley Interdiscip. Rev. Climate Change, 4, 99 106, https://doi.org/10.1002/wcc.204.

National Academies of Sciences Engineering and Medicine, 2018: Science Breakthroughs to Advance Food and Agricultural Research by 2030: A Consensus Study Report of the National Academies of Sciences, Engineering, and Medicine. The National Academies Press, https://doi.org/ 10.17226/25059.

Neto, P. L., 2006: Public perception in contemporary Portugal: The digital representation of space. J. Urban Des., 11, 347-366, https://doi.org/10.1080/13574800600888301.

Nicholson-Cole, S. A., 2005: Representing climate change futures: A critique on the use of images for visual communication.
Comput. Environ. Urban, 29, 255-273, https://doi.org/10.1016/ j.compenvurbsys.2004.05.002.

Niles, M. T., M. Lubell, and V. Haden, 2013: Perceptions and responses to climate policy risks among California farmers. Global Environ. Change, 23, 1752-1760, https://doi.org/ 10.1016/j.gloenvcha.2013.08.005.

,-- , and M. Brown, 2015: How limiting factors drive agricultural adaptation to climate change. Agric. Ecosyst. Environ., 200, 178-185, https://doi.org/10.1016/j.agee.2014.11.010.

_ M. Brown, and R. Dynes, 2016: Farmer's intended and actual adoption of climate change mitigation and adaptation strategies. Climatic Change, 135, 277-295, https://doi.org/10.1007/ s10584-015-1558-0.

O’Neill, S. J., 2013: Image matters: Climate change imagery in US, UK and Australian newspapers. Geoforum, 49, 10-19, https:// doi.org/10.1016/j.geoforum.2013.04.030.

Prokopy, L. S., K. Floress, D. Klotthor-Weinkauf, and A. Baumgart-Getz, 2008: Determinants of agricultural best management practice adoption: Evidence from the literature. J. Soil Water Conserv., 63, 300-311, https:// doi.org/10.2489/jswc.63.5.300.

__ , and Coauthors, 2019: Adoption of agricultural conservation practices in the United States: Evidence from 35 years of quantitative literature. J. Soil Water Conserv., 74, 520-534, https://doi.org/10.2489/jswc.74.5.520.

R Core Team, 2018: R: A language and environment for statistical computing. R Foundation for Statistical Computing, http:// www.R-project.org/.

Risbey, J., M. Kandlikar, H. Dowlatabadi, and D. Graetz, 1999: Scale, context, and decision-making in agricultural adaptation to climate variability and change. Mitig. Adapt. Strat. Global Change, 4, 137-165, https://doi.org/10.1023/ A:1009636607038.

Schattman, R., and Coauthors, 2014: Vermont agricultural resilience in a changing climate: A transdisciplinary and participatory action research (PAR) process. Agroecology, Ecosystems, and Sustainability, N. Benkeblia, Ed., CRC Press/Taylor and Francis, 325-346.

— D. Conner, and V. E. Méndez, 2016: Farmer perceptions of climate change risk and associated on-farm management strategies in Vermont, northeastern United States. Elementa, 4, 1-14, https://doi.org/10.12952/journal.elementa.000131. , G. Roesch-McNally, S. Wiener, M. T. Niles, and D. Y. Hollinger, 2018: Farm Service Agency employee intentions to use weather and climate data in professional services. Renew. Agric. Food Syst., 33, 212-221, https://doi.org/ 10.1017/S1742170517000783.

_- S. Hurley, and M. Caswell, 2019: Now I see: Photovisualization to support agricultural climate change adaptation. Soc. Nat. Resour., 32, 222-228, https://doi.org/ 10.1080/08941920.2018.1530819.

Shaw, A., S. Sheppard, S. Burch, D. Flanders, A. Wiek, J. Carmichael, J. Robinson, and S. Cohen, 2009: Making local futures tangible-Synthesizing, downscaling, and visualizing climate change scenarios for participatory capacity building. Global Environ. Change, 19, 447-463, https://doi.org/10.1016/ j.gloenvcha.2009.04.002.

Sheppard, S. R. J., 2005: Landscape visualisation and climate change: The potential for influencing perceptions and behavior. Environ. Sci. Policy, 8, 637-654, https://doi.org/10.1016/ j.envsci.2005.08.002.

, A. Shaw, D. Flanders, and S. Burch, 2008: Can visualization save the world? Lessons for landscape architects from 
visualizing local climate change. Digital Design in Landscape Architecture, E. Buhmann et al., Eds., Herbert Wichmann Verlag, 29-31.

A. Wiek, J. Carmichael, J. Robinson, and S. Cohen, 2011: Future visioning of local climate change: A framework for community engagement and planning with scenarios and visualization. Futures, 43, 400-412, https:// doi.org/10.1016/j.futures.2011.01.009.

Stoline, M. R., 1981: The status of multiple comparisons: Simultaneous estimation of all pairwise comparisons in one-way ANOVA designs. J. Amer. Stat. Assoc., 35, 134-141, https:// doi.org/10.1080/00031305.1981.10479331.

Tress, B., and G. Tress, 2003: Scenario visualisation for participatory landscape planning-A study from Denmark. Landscape Urban Plann., 64, 161-178, https://doi.org/10.1016/S01692046(02)00219-0.

USDA-NASS, 2013: 2012 Census of Agriculture: Vermont-Table 2: Market value of agricultural products sold including landlord's share and direct sales. U.S. Department of Agriculture National Agriculture Statistics Service, accessed 18 September 2017, https://www.nass.usda.gov/Publications/AgCensus/2012/ Full_Report/Volume_1,_Chapter_1_State_Level/Vermont/. , 2017: Certified Organic Survey 2016 Summary. U.S. Department of Agriculture National Agriculture Statistics Service Rep.,
163 pp., https://www.nass.usda.gov/Publications/Todays_Reports/ reports/census17.pdf.

Visscher, R. S., J. I. Nassauer, and L. L. Marshall, 2016: Homeowner preferences for wooded front yards and backyards: Implications for carbon storage. Landscape Urban Plan., 146, 1-10, https://doi.org/10.1016/j.landurbplan. 2015.09.001.

Walthall, C., and Coauthors, 2012: Climate change and agriculture in the United States: Effects and adaptation. USDA Tech. Bull. 1935, 186 pp.

Warren-Kretzschmar, B., and C. Von Haaren, 2014: Communicating spatial planning decisions at the landscape and farm level with landscape visualization. IForest, 7, 434-442, https:// doi.org/10.3832/ifor1175-007.

Wilhelm, J., 2017: Exploring the socio-ecological dimensions of agricultural expansion in New Hampshire. Ph.D. dissertation, University of New Hampshire, 144 pp.

Willingham, D. T., E. M. Hughes, and D. G. Dobolyi, 2015: The scientific status of learning styles theories. Teach. Psychol., 42, 266-271, https://doi.org/10.1177/0098628315589505.

Wolfe, D., and Coauthors, 2018: Unique challenges and opportunities for northeastern U.S. crop production in a changing climate. Climatic Change, 146, 231-245, https://doi.org/10.1007/ s10584-017-2109-7. 